\title{
Five years ago ...
}

\section{Comparison charts as a public relations tool}

\author{
by Janet R. Cottrell and Frank M. Wojcik
}

$\mathrm{T}$ he escalating pace of change occurring in most academic libraries can make it difficult to determine the actual effects of our efforts. Preparing a summary chart comparing current information resources and services with those offered five years ago is an easy way to help patrons, administrators, and staff see the overall effects over time.

Whether the issue is reelecting someone for public office or assessing library and information services, the question people really want answered is "Are we better off now than we were five years ago?" In the fastchanging world of academic librarianship, it is easy to lose sight of such a basic question. Our accelerated rate of change, our continual evolution, and our preoccupation with the here and now sometimes make it difficult to step back and determine the actual effects of our initiatives-to see the big picture.

However, such assessment is crucial. Few libraries can afford to implement new initiatives indefinitely without some indication of their worth. Librarians who make no effort to assess the value of changes they have implemented risk having their patrons and funders form their own opinions in the absence of accurate information.

\section{Assessment methods}

Assessment methods vary in terms of scope, difficulty, expense, and usefulness. Perhaps the most ambitious and comprehensive method is outcome assessment, in which the impact on student and faculty is measured in terms of effectiveness, quality, and so on. These measures can be difficult to develop, implement, and interpret, and frequently require hard-to-gather longitudinal data. Attitudinal assessments, such as focus groups or satisfaction surveys, are another useful measure. They can be relatively inexpensive to develop and deploy, and their interpretation can be fairly straightforward, but they are, in the end, measures of opinion, not fact.

Another tool to assess the value of programmatic or resource changes-a very simple and inexpensive one-is a well-formatted comparison chart highlighting factual differences in services, collections, access, or other measures between two points in time.

The topics that any given library chooses to highlight will depend on the kinds of changes made in recent years, but in general the chart should reflect areas of dramatic change, features whose introduction may have been controversial, topics that are particularly important to the library's mission, and so on. Typical topics that might be highlighted include changes in the physical collection (types, amounts, usage); changes in the online collection; changes of physical size or layout; changes in staffing, hours, or services provided; and changes in consortial arrangements or management structure.

\section{About the authors}

Janet $R$. Cottrell is director of information access, Library and Information Services, and Frank M. Wojcik is director of information resources, Library and Information Services, at Kenyon College, e-mail: cottrellj@kenyon.edu and wojcikf@kenyon.edu 


\section{The "Five Years Ago" chart}

When Frank Wojcik, one of the directors of Kenyon College's merged library and computing services organization, known as Library and Information Services, created a comparison chart in 2000, he highlighted the tremendous expansion in print and online materials now accessible through the college's consortial agreements $^{1}$ (see Table 1). The differences over time in the scope of print monograph titles, journal titles, and databases speak for themselves. ${ }^{2}$ The chart includes other striking differences, such as an increase in the number of degreed librarians on the staff. Finally, as a sort of teaser, he included without comment a statistic reflecting the decrease in materials checked out of the library; this entry never fails to start an interesting discussion.

First prepared for a board of trustees subcommittee meeting, Kenyon's "Five Years Ago" chart has served in many settings. The chart, or information from it, has been used in faculty advisory committee meetings, a division-wide staff meeting, and an interview in a campus publication. It is posted on the division's Web site and has come up in discussion with prospective employees. Facts from the chart have been pulled out for use in "Did you know ..." signs posted near the reference and current periodicals areas.

\section{Table 1: Changes in information resources at Kenyon College in the last five years (May 2000)}

Five years ago, the library had a computerized card catalog, providing access to Kenyon's book collection of 300,000 titles.
Today, the library has a new Web-based catalog, which includes local Kenyon holdings, plus access to the CONSORT and OhioLink collections: a total of 7 million titles. Besides using the catalog as a finding aid for these collections, the Kenyon community is able to link directly to thousands of fulltext electronic journals and books from the cata$\log$.

Five years ago, the library offered OCLC's FirstSearch, Lexis/Nexis, and 14 CD-ROM-based databases. Generally, searching these databases had to be performed in the library, and often the search had to be conducted by a librarian.

Five years ago, the library subscribed to approximately 1,250 periodicals and had begun canceling many titles because of budgetary constraints.

Five years ago, Kenyon's library made heavy use of staff-mediated interlibrary loan services to provide access to materials not locally available. This process was slow and labor intensive.
Today, we offer more than 125 major databases. Within the past year we have added such titles as the ATLA Religion Index, ABC Political Science, CIS History Universe, IT Knowledge, Humanities Abstracts, INSPEC, and many others. These citation databases link to the electronic full-text of atticles, wherever possible. Through our patron authentication software, members of the Kenyon community can search most of these databases from anywhere in the world.

Today, the library subscribes to more than 4,500 periodicals, including more than 3,200 journals in electronic format. Some of our electronic subscriptions have reinstated the paper subscriptions we canceled in the 1990 s.

Today, Kenyon continues to use mediated interlibrary loan, but to a much smaller extent than before. Library users are able to borrow books directly from CONSORT, OhioLink, and the Center for Research Libraries without the assistance of library staff. Delivery of these items takes only a few days. In addition, our expanded journal hold ings make us less dependent on other institulions for access to periodical literature.

(continued on next page) 
Prepared fairly easily using data collected for routine annual surveys, the chart has long repaid the effort invested in its preparation. As a concise information piece, a quick reference chart, and a prompt for substantive discussion, the "Five Years Ago" chart has served us well.

\section{Notes}

1. Kenyon College is a member of the Five Colleges of Ohio consortium, which also includes the College of Wooster, Denison University, Oberlin College, and Ohio Wesleyan University. The Five Colleges collaborate on an information literacy project, a foreign language technology project, a remote library storage facility, a cooperative collection development project, and CONSORT-a shared integrated library system. Kenyon also belongs to OhioLINK, a statewide consortium including the libraries of 80 colleges and universities. OhioLINK's direct borrowing program provides access to more than 31 million library items statewide, and many of Kenyon's digital information resources, electronic journals, electronic books, digital images, and research databases are acquired through OhioLINK's cooperative acquisitions programs.

2. Obviously the numbers on the chart presented here represent a moment in time in 2000 , and many statistics have changed dramatically since then. For example, we now have access to more than 5,700 journals and 24,000 electronic books, and we employ 14 librarians. Digital images, which were not mentioned in the chart, have become an important part of our collection. We are in the process of updating the chart to reflect these new trends. It is always possible, given current economic conditions, that we will see a contraction of library budgets and that consortial purchasing power, in particular, may be adversely affected. Also, due to marketplace variables, some vendors mentioned in the chart, e.g., IT Knowledge, have not remained viable.

\section{Table 1 (continued)}

Five years ago, Kenyon had developed an extensive slide library in support of the college curriculum.
Today, the slide library is even larger and our slide collection is supplemented with more than 50,000 digital images from the OhioLink Digital Media Center. Locally, we are planning image digitization projects and improved access to our entire image collection.

Five years ago, Kenyon's Government Documents collection was cataloged selectively; much of it was not cataloged at all. This made the collection difficult to access by our users.

Five years ago, library users always had to visit the library in orcler to use course reserve materials.

Five years ago, Kenyon employed eight librarians.

Five years ago, all of our library cataloging was done locally, using OCLC as a cataloging resource.

Five years ago, the library circulated more than 77,000 items to the Kenyon community.
Today, every newly arrived Government Document is cataloged. In addition, Kenyon is participating in an award-winning historical documents cataloging project with the other Five Colleges of Ohio libraries. Access to documents is easier and more efficient than ever before.

Today, Kenyon has established an electronic reserves system, which the community can access from anywhere, at any time.

Today, Kenyon employs 13 librarians. This number is up from five librarians two years ago.

Today, much of our cataloging is done locally, but some is outsourced and some is done in cooperation with OhioLink and the Five Colleges of Ohio consortia.

Today, total circulation for the year, including items borrowed from OhioLink and CONSORT, will total approximately 68,000 items. This year Kenyon borrowers will borrow more than 25 percent of their books from CONSORT and OhioLink. 


\section{Celebrating 70 Years of Publishing Excellence!}

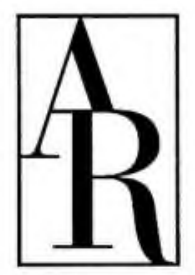

\section{A N N U A L R E VIEW S}

Intelligent Synthesis of the Scientific Literature

Your Key to Relevant Research in Biomedical, Physical and Social

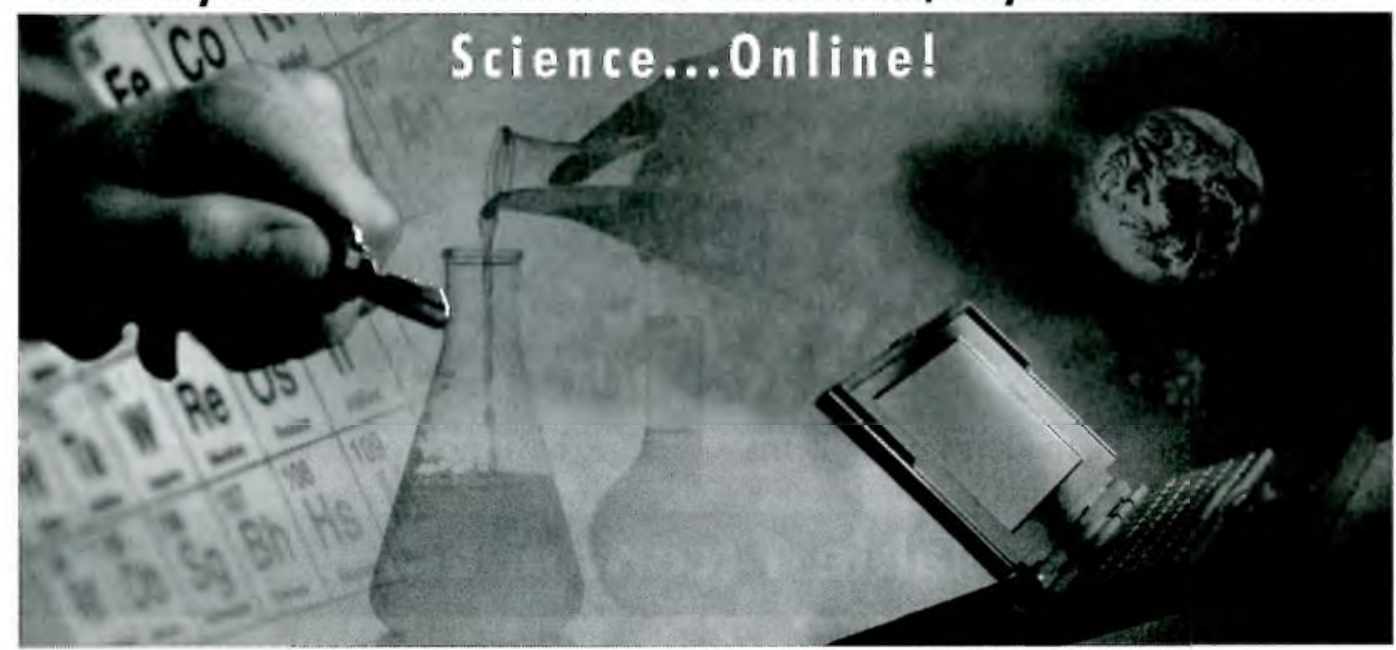

Annual Reviews is the Definitive Resource for Research!

For 70 years, Annual Reviews has synthesized the vast amount of primary research

literature to bring you authoritative review articles in 29 disciplines of science.

\section{We have Site license solutions you can count on...}

*Tailored and Affordable Single and Multiple Site License Agreements to meet

your Patrons' Research and Academic Needs

${ }^{*}$ Continuous and Seamless Online Access

* Links to Cited Research

*Powerful Search Capabilities

\section{For Site License or Consortia Information}

Contact Annual Reviews, and ask for the Site License Department.

Call toll free: 800.523 .8635

Call worldwide: 650.493 .4400

Fax: 650.424.0910

Email: sitelicense@annualreviews.org

w w w. an nua Ireviews.org 